\title{
Cocimiento para los ojos por complicaciones de la viruela en el Virreinato de la Nueva Granada en el siglo XVIII
}

\section{Eye decoction due to smallpox complications in the Viceroyalty of New Granada in the $18^{\text {th }}$ century}

\author{
Eric Y. Canaria-Ascencio ${ }^{1 *}$, Jorge Uribe-Vergara², Julio C. Martínez-Lozano ${ }^{3}$, Alberto Gómez-Gutierrez ${ }^{4}$ y \\ Ignacio Briceño-Balcázar ${ }^{3}$
}

${ }^{1}$ Facultad de Medicina, Universidad de La Sabana; ${ }^{2}$ Departamento de Ciencias Sociales de la Pontificia Universidad Javeriana; ${ }^{3}$ Área de Biociencias, Facultad de Medicina, Universidad de La Sabana; ${ }^{4}$ nstituto de Genética Humana, Facultad de Medicina, Pontificia Universidad Javeriana. Colombia

\section{Resumen}

Objetivo: Presentar una receta médica del siglo XVIII, utilizada en los tiempos del Virreinato de la Nueva Granada, que describe el tratamiento de complicaciones oculares de viruela, especificando el uso de la linaza (Linum usitatissimum), el azafrán (Crocus sativus) y la malva de Castilla (Malva sylvestris) en su preparación. Materiales y métodos: Búsqueda en el archivo histórico de la Biblioteca Octavio Arizmendi Posada, en la Universidad de La Sabana (Chía, Colombia), donde se conserva una colección de un centenar de recetas médicas del siglo XVIII. Se realiza una transcripción de una de ellas, titulada "Cocimiento para los ojos», con una ulterior revisión de la literatura científica pertinente. Conclusiones: Esta receta médica colonial muestra su utilidad para aliviar los síntomas oculares de la viruela, como un efectivo emoliente de uso externo, como un claro ejemplo de la terapéutica necesaria. Además, esta prescripción también debería reconocerse como un ejemplo documental de la evolución histórica de la medicina y la labor de la herbolaria desde los tiempos coloniales de los entonces territorios de ultramar de la Corona española.

Palabras clave: Historia de la Medicina. Colombia. Siglo XVIII. Viruela. Enfermedad Ocular. Prescripciones.

\begin{abstract}
Objective: To present an $18^{\text {th }}$ century prescription used in the Viceroyalty of New Granada, which describes the treatment of ocular complications of smallpox, specifying the use of linseed (Linum usitatissimum), saffron (Crocus sativus) and mallow of Castilla (Malva sylvestris) in its preparation. Materials and Methods: Search in the historical archive of the Octavio Arizmendi Posada Library at the University of La Sabana (Chí, Colombia), where a collection of around a hundred prescriptions of the $18^{\text {th }}$ century is preserved; transcribing one of them entitled "Cocimiento para los ojos", with a subsequent review of relevant scientific literature. Conclusions: This colonial prescription shows its usefulness to relieve ocular symptoms of smaIIpox, as an emollient effective for external use, as a clear example of the therapy required. In addition, this prescription should also be recognized as a documentary example of the historical evolution of medicine and the work of herbal medicine, from the colonial times of the then overseas territories of the Spanish Crown.
\end{abstract}

Key words: History of Medicine. Colombia. $18^{\text {th }}$ Century. Smallpox. Eye Disease. Prescriptions.

Correspondencia:

*Eric Canaria Ascencio

Fac. Medicina. Campus Puente del Común

Km.7, AP. Norte de Bogotá, Chía Fecha de recepción: 04-06-2018

Disponible en internet: 02-01-2019

C.P. 50008, Cundinamarca, Colombia Fecha de aceptación: 31-07-2018

Rev Mex Oftalmol. 2019;93(1):31-34

E-mail: ericcaas @ unisabana.edu.co DOI: 10.24875/RMO.M18000048 www.rmo.com.mx
0187-4519/@ 2018 Sociedad Mexicana de Oftalmología. Publicado por Permanyer México. Este es un artículo Open Access bajo la licencia CC BY-NC-ND (http://creativecommons.org/licenses/by-nc-nd/4.0/). 


\section{Introducción}

El archivo histórico de la biblioteca Octavio Arizmendi Posada en la Universidad de la Sabana (Chía, Colombia) cuenta con una colección de un centenar de recetas médicas coloniales del siglo XVIII, donadas por el Padre Cipriano Rodríguez Santa María, epónimo institucional del archivo'.

La llegada de los exploradores y conquistadores españoles al continente americano a finales del siglo XV propició un intercambio cultural, étnico y tecnológico -entre otros -, que cambió para siempre los destinos de millones de personas a ambos lados del océano Atlántico. Entre los diversos elementos aportados por los peninsulares al continente americano, se destacan las enfermedades infecciosas, como la viruela, que tuvieron un papel preponderante en la modulación de la población, con una elevada tasa de morbilidad y mortalidad $^{2}$.

La viruela es una enfermedad causada por el microorganismo llamado virus Variola ${ }^{3}$, con dos variedades, Variola maior y Variola minor, con demostrada asociación directa con la mayor o menor gravedad de su presentación clínica. Se presenta con un pródromo de fiebre, malestar general, dolor de cabeza, dolor en el cuerpo, con la consiguiente aparición de una erupción maculopapular, que progresa a pústulas y luego a lesiones costrosas 4 .

Esta enfermedad presenta múltiples complicaciones, desde leves a ominosas, y las más comunes son las respiratorias, con un rango que abarca desde bronquitis hasta una neumonía fatal, así como infecciones bacterianas secundarias y encefalitis. Adicionalmente, se pueden formar pústulas en los párpados, conjuntiva y córnea que llevan a conjuntivitis, queratitis, úlcera corneal, iritis, iridociclitis y atrofia óptica, además de una eventual ceguera secundaria ${ }^{5}$.

A finales del siglo XVIII, en el entonces Virreinato de la Nueva Granada, antes de la expedición sanitaria de las autoridades peninsulares denominada «Expedición de la Vacuna»², la viruela era uno de los principales azotes sanitarios del viejo y del nuevo mundo. Al no distinguir grupos étnicos ni condición social, tuvo un fuerte impacto en las poblaciones indígenas amerindias, donde se presentó la mayor tasa de mortalidad, eventualmente en función de una ausencia de inmunidad frente a los inmigrantes europeos, lo que allanó el camino del descubrimiento de América para la dominación colonial española ${ }^{2}$. Por esta razón, fue necesario en esos tiempos el uso de preparados americanos para paliar las complicaciones de la viruela'.
La situación mostraría visos de mejorar con la realización de la Real Expedición Filantrópica de la Vacuna entre 1803 y 1806, organizada por Francisco Javier Balmis (1753-1819) y José Salvany y Lleopart (1778$1810)^{6}$, y autorizada por el rey Carlos IV de España, como consecuencia del descubrimiento de carácter preventivo del afamado Edward Jenner (1749-1823) en $1796^{2}$. La iniciativa española se vio reflejada en la formación de organizaciones administrativas en los territorios americanos del imperio español, tales como la Junta de la Vacuna en la ciudad de Tunja en la Nueva Granada, encargada de la inmunización, entidad disuelta en $1810^{7}$. Se deben destacar también los aportes de José Celestino Mutis (1732-1808) y de su sobrino Sinforoso Mutis Consuegra (1773-1822) a la difusión de la vacuna de la viruela en la Nueva Granada en la transición del siglo XVIII al siglo XIX ${ }^{8,9}$.

Entretanto, donde no se disponía de la vacuna antivariólica, se afrontaban sus síntomas y complicaciones -específicamente oculares- por medio de diversas recetas médicas usadas por galenos coloniales, muchos de ellos empíricos y sin formación académica. De acuerdo con lo anterior, se dispone hoy de un extracto original de una de estas recetas que se puede observar en la Figura $1^{1}$ que se transcribe literalmente y se describe a continuación:

\section{Cocimiento para los ojos}

Linaza y ojas de malva de castilla, con agua de la tinaja, se hace cocimiento que quede algo baboso; en un poco de este cocimiento se echan unas ebras de azafran seco, que no tenga aceite desuerte que dé al cocimiento una color no muy encendida.

Si no hubiera el azafran seco, se seca entre unos papeles al sol, remudando los papeles hasta que esté seco.

Con un poco de este cocimiento tibio se lavan los ojos siempre que se necesitase quatro ó cinco veces al día, ó mas si fuere menester.

Con el mismo cocimiento tibio se lavan las narices, y oídos, si se criasen dentro viruelas y hubiese necesidad de ello.

La relevancia del presente artículo reside en que explora y fundamenta el entendimiento actual de algunos medicamentos utilizados en la historia de la oftalmología. El objetivo principal de nuestro trabajo es presentar el contexto de formulación de una receta médica del siglo XVIII en el Virreinato de la Nueva Granada, la cual fue utilizada para tratar los síntomas 


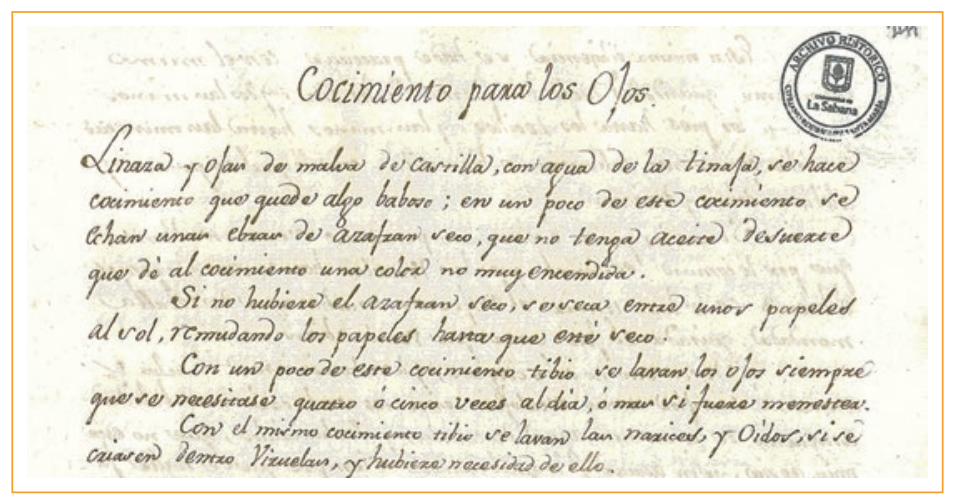

Figura 1. Receta Médica "Cocimiento para los ojos"1.

oculares de la viruela, y también analizar si sus ingredientes en conjunto son útiles para el mejoramiento de esos síntomas descritos.

\section{Materiales y métodos}

Se procedió a realizar una búsqueda documental en el archivo histórico de la Biblioteca Octavio Arizmendi Posada en la Universidad de La Sabana, en la que se encuentra la receta "Cocimiento para los ojos". Secundariamente se realiza una revisión de la literatura disponible sobre los elementos o las sustancias que contenía la fórmula, en bases de datos.

\section{Análisis del documento fuente}

La función de este preparado tiene relación directa con las complicaciones oftalmológicas descritas, exceptuando, por razones anatómicas, la atrofia óptica.

En primer lugar, es necesario definir el término "cocimiento» que, según el diccionario de la Real Academia de la Lengua Española ${ }^{10}$, hace referencia a «líquido cocido con hierbas $u$ otras sustancias medicinales, que se hace para beber y para otros menesteres".

Entonces, en la preparación de esta receta interviene:

- La linaza (Linum usitatissimum) ${ }^{11,12}$ : Es una herbácea de la familia de las lináceas, cuyo tallo es usado para hacer materiales textiles y la semilla cuenta con diversas aplicaciones medicinales y gastronómicas. En este caso se usa la semilla, que al entrar en contacto con el agua produce un líquido viscoso - «baboso», como es descrito en el documento- como primer componente. En consecuencia, la linaza se puede identificar como excipiente para dar forma y volumen a la mezcla, aunque también como emoliente (para ablandar, relajar y suavizar las partes inflamadas).

- El azafrán (Crocus sativus) ${ }^{12,13:}$ Es producto de los pistilos de esta flor de la familia iridácea, cuyos usos principales han sido como colorante y aromatizante gastronómico. Este condimento tiene el antecedente de ser un producto de interés comercial elevado, con los principales cultivos a nivel mundial en Irán, España, Marruecos, India y Grecia. En relación con la receta, y al conocimiento actual de este derivado vegetal, este se habría utilizado solamente para dar color y aroma'.

- La malva de Castilla (Malva sylvestris) ${ }^{11,12}$ : Es una herbácea de la familia de las malváceas, con aplicaciones medicinales. Como su nombre taxonómico indica, es de crecimiento silvestre, y es abundante en zonas como baldíos, áreas de cultivo, márgenes de caminos, etc. Se encuentra en Europa, Asia occidental, norte de África y en el continente americano. Se usaba, a todas luces, el contexto del preparado, como emoliente.

Se observa así que la combinación de estos ingredientes botánicos, disponibles en el Virreinato de la Nueva Granada ya sea como cultivos, plantas silvestres o elementos importados ${ }^{14}$, era útil para calmar el dolor y la inflamación en los ojos, síntomas secundarios de la infección por viruela, así como también para una aplicación secundaria en las fosas nasales y los conductos auditivos externos, y contribuía a una mejoría sintomática, sin descuidar su clara indicación externa tal y como fue descrita en el documento. Estas disposiciones fueron reguladas por la institución del protomedicato $^{15}$, de origen peninsular, pero adaptadas a la situación local de aquel tiempo.

Una recomendación que complementaría esta receta colonial corresponde al uso de ácido bórico ${ }^{3}$ por sus 
propiedades antisépticas para aliviar las infecciones oculares asociadas como resultado del frotamiento de los ojos por los afectados de viruela.

\section{Conclusión}

Antes de concluir, debe precisarse el estado actual de la viruela, enfermedad erradicada en el mundo según la Organización Mundial de la Salud en la década de 1980 del siglo XX4.

En cuanto a la receta médica colonial analizada en el presente artículo, se pudo demostrar su utilidad para el alivio de los síntomas oculares de la viruela, como un efectivo emoliente de uso externo. También debe reconocerse como un ejemplo documental de la evolución histórica de la medicina desde los tiempos de los entonces territorios de ultramar de la Corona española.

Deben tenerse en cuenta los usos empíricos de las plantas medicinales en sus respectivos contextos históricos para fundamentar adecuadamente los cuidados requeridos en el tratamiento de los síntomas de afecciones diversas en tiempos presentes y pretéritos, y así reforzar, a través de estas prácticas, la tradición de preparados vegetales y minerales para un alivio efectivo El valor de la herbolaria en la historia de la medicina ha sido fundamental.

Con el presente análisis, se evidencia el loable esfuerzo de las autoridades sanitarias coloniales del Virreinato de la Nueva Granada (actual República de Colombia) en el empleo de recetas como la que se describe aquí, en la búsqueda de la terapéutica disponible para aliviar los síntomas de padecimientos incapacitantes y adversos, en tiempos en los que el conocimiento médico y científico estaba apenas en una fase que hoy consideramos primaria.

Finalmente, debe destacarse el esfuerzo para la conservación de estos documentos por parte del archivo histórico de la Biblioteca Octavio Arizmendi Posada de la Universidad de La Sabana. Estos documentos tienen un indudable y valioso valor histórico, y su consulta permite recrear, en buena parte, la evolución de la medicina del siglo XVIII al siglo XIX en el entonces Virreinato de la Nueva Granada.

\section{Conflicto de intereses}

No se reporta conflicto de intereses por parte de ningún autor.

\section{Financiamiento}

La investigación y proceso de publicación fueron financiadas por las universidades a las cuales los autores están afiliados.

\section{Agradecimientos}

Los autores reconocen la generosa asistencia ofrecida por Marcela Revollo Rueda, directora de los Archivos Históricos de la Biblioteca Octavio Arizmendi Posada en la Universidad de La Sabana.

\section{Bibliografía}

1. Universidad de la Sabana. Archivo Histórico Cipriano Rodríguez Santa María, Fondo Manuel María Mosquera. Caja 10 - Carpeta 2 - 247 recto.

2. Díaz $O$. La viruela y el hombre. Más allá del humanismo médico. Dendra médica. Revista de Humanidades. 2011;10(1):21-39.

3. Carrada Bravo T. La viruela: diagnóstico, prevención y tratamiento. Piel. 2003;18(5):240-51.

4. Fenner F, Henderson DA, Arita I, Jezek Z, Ladnyi ID. Smallpox and its Eradication Geneva: World Health Organization; 1988.

5. Franco Paredes C, del Río C, Nava Frías M, Rangel Frausto S, Téllez I, Santos Preciado Jl. Enfrentando el bioterrorismo: aspectos epidemiológicos, clínicos y preventivos de la viruela. Salud Pública de México. 2003;45(4).

6. Balaguer Perigüell E, Ballester Añón R. En El Nombre De Los Niños: La Real Expedición Filantrópica De La Vacuna (1803-1806). Monografías de la Asociación Española de Pediatría; 2003.

7. Gutiérrez Beltrán AC. Las epidemias de viruela en la ciudad de tunja: 1780-1810. La junta de vacuna. Bogotá: Instituto Colombiano de Antropología e Historia - ICANH, Area de Historia Colonial; 2007.

8. Palacios Sánchez L. Algunos aspectos relacionados con José Celestino Mutis y la medicina. Revista Ciencias de la Salud. 2008; 6(2).

9. España G. José Celestino Mutis: El sabio de la vacuna. $1 .^{\mathrm{a}}$ ed. Bogotá: Colciencias; 1998

10. Diccionario de la lengua española. Real Academia Española. [Online]; 2018. Disponible en: http://dle.rae.es/?id=9angWro.

11. Jiménez R. SL, Fonnegra Gómez R. Plantas medicinales aprobadas en Colombia. 2. ed. Medellín: Editorial Universidad de Antioquia; 2006.

12. Linnaeus CV. Botanicus. [Online]. Holmiae (Estocolmo): Imprensis Laurentii Salvii; 1753. [Edición Original en Latín]. Disponible en: http://www. botanicus.org/title.aspx?bibid=b12069590.

13. Negbi M. Saffron: Crocus sativus L. 1. a ed. Jerusalem: CRC Press; 1999.

14. Pita Pico R. Las boticas en el Nuevo Reino de Granada a finales de periodo colonial: el lento camino hacia la modernidad. Medicina. 2015;37(3):223-41.

15. Gardeta Sabater P. El Real Tribunal del Protomedicato en la Audiencia de Santa Fe durante la segunda mitad del XVIII: un acercamiento al estudio de las transformaciones de esta institución española. Dynamis: Acta Hispanica ad Medicinae Scientiarumque Historiam Illustrandam. 1992;12:209-24. 